\title{
38
}

\section{Bio-Sudoku 4}

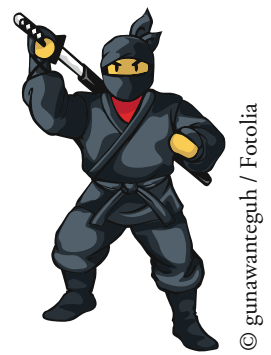

Ein Buchstaben-Sudoku wird wie ein gewöhnliches Sudoku gelöst. Der Unterschied: Statt mit den sonst verwendeten Zahlen von 1 bis 9 wird dieses Rätsel mit folgenden neun Buchstaben ausgefüllt: $\mathbf{Y}-\mathbf{O}-\mathbf{P}-\mathbf{C}-\mathbf{E}-\mathbf{A}-\mathbf{L}-\mathbf{H}-\mathbf{T}$

\begin{tabular}{|r|r|r|r|r|r|r|r|r|}
\hline Y & C & & T & E & ${ }_{10}$ & ${ }_{2}$ & H & \\
\hline & $8^{2}$ & & & C & & A & L & Y \\
\hline H & O & A & & Y & L & C & & \\
\hline & ${ }_{3}$ & P & A & & & Y & T & 6 \\
\hline 9 & & & & & & & A & O \\
\hline & & E & H & & & & & L \\
\hline & & & & & & L & O & A \\
\hline L & H & & & & & & & \\
\hline & & & C & & T & H & Y & \\
\hline
\end{tabular}

Lösung:

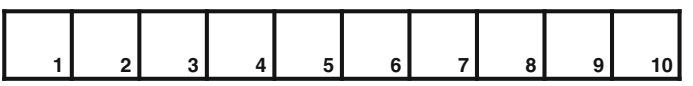

Tipp Das Lösungswort benennt eine Tierklasse mit rund 10.000 bekannten Arten. 